\section{What's in a name?}

Robbie was rightly and loyally devoted to his family name. When he accepted a knighthood at the second time of its being offered to him I asked him what he was to be called-Robbie, Robin, Robert, or Theodore? "Well," he said, "what was inappropriate as a name for me at my prep school might now come into use." So Sir Theodore he became. "Your father would have been pleased," I said. "Did you know my father?" he asked.
I did not. But I knew that as Dr Fortescue Fox of Strathpeffer spa he had been a lifelong hero of my 95 year old grandmother for long after she had been able to pay her yearly visit to him for treatment of her arthritis. Just as Dr Fortescue Fox was a hero of my grandmother, so his son Theodore is a hero of mine.

Sir Theodore Fox died in 1989; obituaries were published in the $B M \mathcal{F}$ (1 July, p 47) and Lancet (1 July, p 56).

\title{
Medical imagery in the art of Frida Kahlo
}

\author{
David Lomas, Rosemary Howell
}

Frida Kahlo held her first solo exhibition in New York in 1938. Included were paintings that narrate her experience of a miscarriage six years earlier in Detroit, where she had accompanied her husband, the Mexican mural painter Diego Rivera. Reviewing the exhibition Howard Devree, an art critic for the New York Times, dismissed Kahlo's work as "more obstetrical than aesthetic." Underlying this reproach is an attitude that art should not concern itself with obstetrics, a view that any cursory glance at Western art would confirm. To describe artistic creation by using metaphors of gestation and birth is commonplace, yet to depict such events is tacitly proscribed. In Western art scenes of childbirth are rare and visual accounts of abortion or miscarriage non-existent. They have remained the province of medical texts. Openly flouting this convention, Kahlo produced a unique body of images such that Rivera could proclaim her "The only human force since the marvellous Aztec master sculpting in black basalt who has given plastic expression to the phenomenon of birth."

In the culture to which Kahlo belonged miscarriage was a source of shame: the abject failure of a socially conditioned expectation of motherhood and a travesty of creation in which birth yields only death and detritus. No rituals exist to commemorate the loss associated with miscarriage, which is thus relegated to a private domain of silent grief. ${ }^{3}$ By speaking out Kahlo

BrMed f 1989;299:1584-7 articulated the unspeakable in a hybrid language derived partly from artistic traditions but also from textbooks of anatomy and obstetrics.

Kahlo's medical history is a catalogue of misfortune. She was born in 1907 and was affected by poliomyelitis, which left her right leg withered and her spine scoliotic. When she was 18 a tram accident caused devastating injuries. She was impaled through her pelvis by a steel bar and sustained multiple fractures of the spine, pelvis, right leg, and foot. In subsequent years she underwent numerous orthopaedic operations in vain atttempts to alleviate pains in her back and right leg, which was eventually amputated. Her death at age 47 followed soon afterwards. More than one pregnancy was terminated by therapeutic abortion, and she had two (possibly three) first trimester miscarriages of uncertain relation to the accident. Though the severe penetrating injury may have caused uterine deformity, her debilitated physical state manifesting in chronic infections and anaemia was a more probable contributory factor. Her best documented pregnancy was proceeded with only after much equivocation and weighing of the potential risks of a caesarean section. It ended abruptly, however, in a miscarriage in 1932.

Henry Ford Hospital (fig 1) was painted shortly afterwards. Kahlo lies naked on a hospital bed in a pool of blood. The title alludes to the medical setting yet her bed is displaced into a desolate landscape to heighten the sense of isolation and vulnerability. Superimposed on this scene is an array of objects referring to the miscarriage; some evoke it literally while others allude more obliquely and subjectively to the event. These are depicted in a larger scale and a contrasting diagrammatic idiom. In this painting Kahlo is the hapless victim of an event over which she exerts no control. The impression of helpless isolation is aggravated by the lack of a visual language to express her trauma. The awkward disjuncture between two pictorial modes - schematic and naturalistic-seems to gesture towards a grief that is representable only as discontinuity. Where the newspaper critic recoiled in distaste before this spectacle one sees Kahlo striving to render visible a blindspot of high cultural vision. Medical imagery helps her to achieve this; immediately after the miscarriage she began foraging in obstetric texts and evidently drew the fetus and pelvis from this source. Yet its incapacity to evoke the subjective dimension of her response is indicated by the sharp discrepancy between these prosaic forms and the snail, a private allusive reference.

Frida and the Miscarriage, 1932 (fig 2) has a similar composition. The naked body is central and once again surrounded by axially arranged forms: a fetus (the umbilical cord wrapped like a bandage around her damaged right leg), dividing cells, and growing plants. The effect is harmoniously balanced, however, where formerly it was disjointed. Leaves shaped like phalluses 
and hands echo equivalent shapes of the fetus opposite. The mutually excluding worlds of female procreation and masculine artistic creation (Kahlo holds aloft an artist's palette) reunite in her body, which is assimilated to cyclical forces of nature. Tears suspended like jewels from her cheeks become raindrops and the moon weeps in unison with Kahlo, who no longer stands utterly alone.

Her pictures are replete with wombs and lactating breasts, symbols of maternal fecundity, yet Kahlo departs from a facile stereotype of womanhood to register a more complex reality. Pregnancy was, on one level, much desired by her but was fraught with risk and brought only pain and distress. Her ambivalence can be gauged in a third image related more distantly to the miscarriage, My Birth, 1932 (fig 3). Painted shortly after her mother's death, it conflates two chronologically separate events by representing her both giving birth and being born. A picture of The Mater Dolorosa - the mother of Christ whose grief for her lost son is shown by tears and flesh pierced by daggers ${ }^{4}-$ symbolically substitutes for the mother

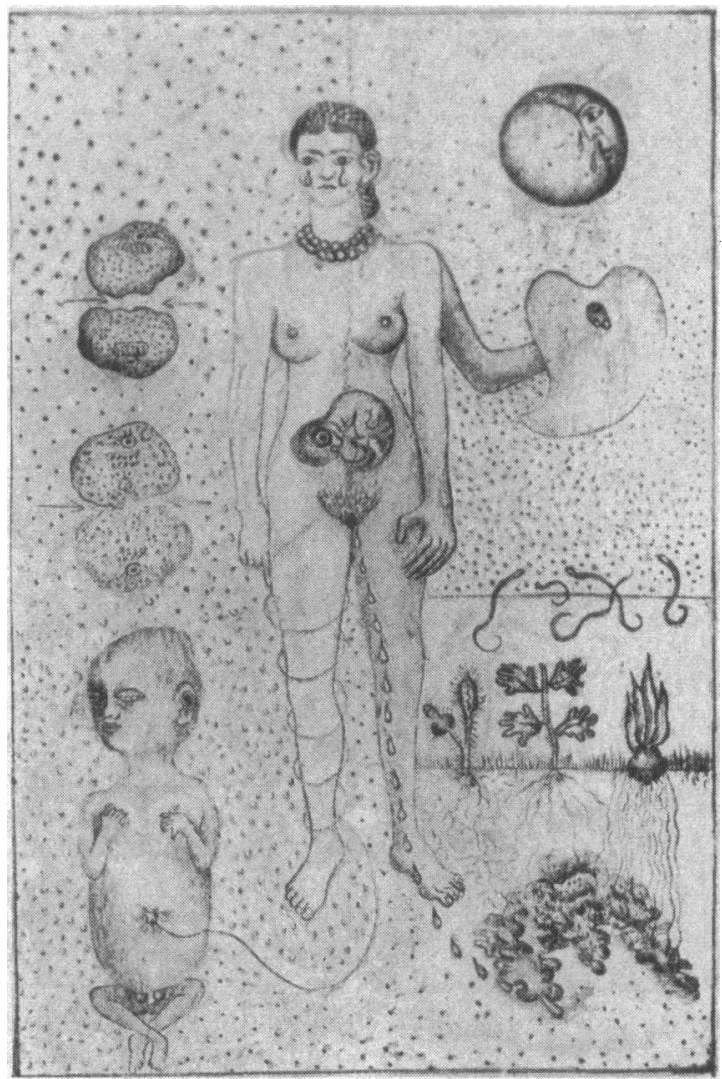

FIG 2-Frida and the miscarriage, 1932. Collection of Dolores Olmedo, Mexico City

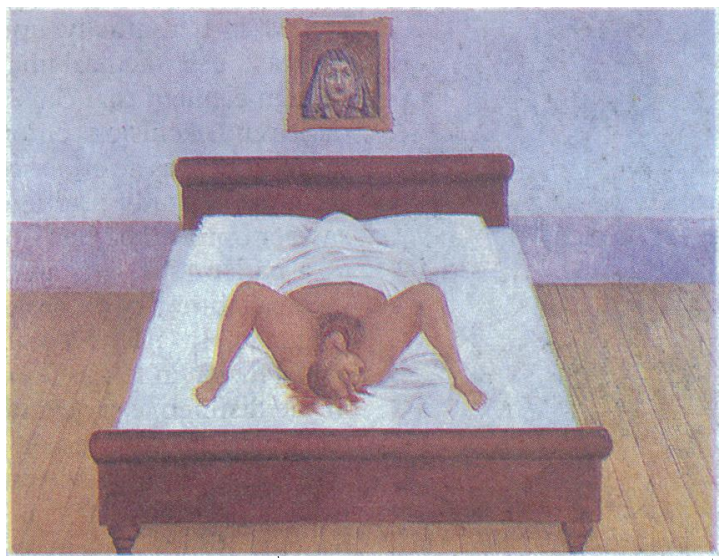

FIG 3-My birth, 1932. Private collection, United States

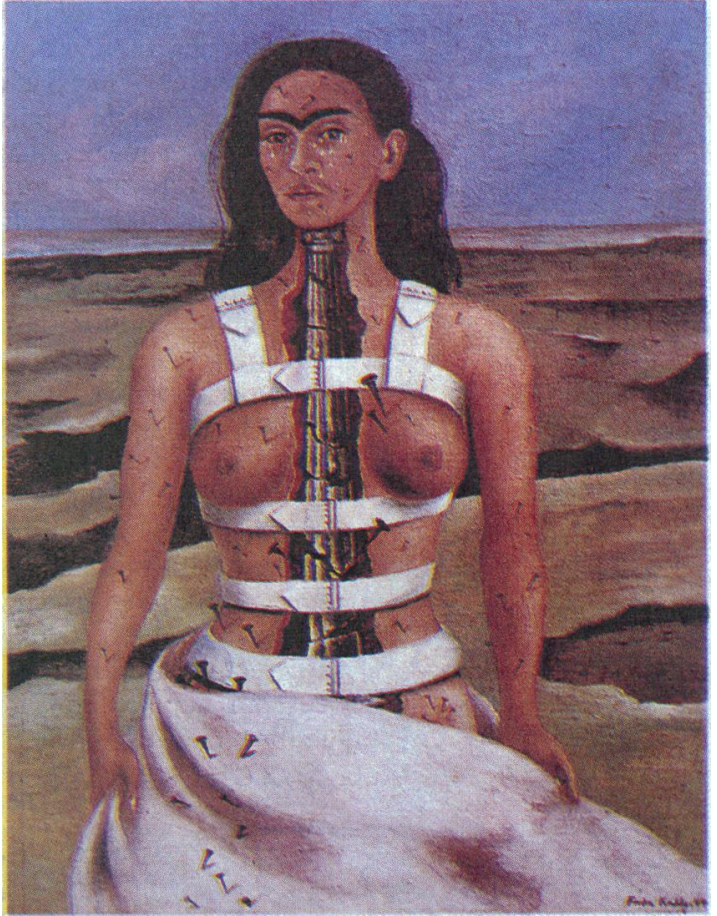

FIG 4-The broken column, 1944. Collection of Dolores Olmedo, Mexico City

whose head is ominously concealed by drapery. The spectre of death and loss thus hangs over the very moment of birth. From Henry Ford Hospital to Frida and the Miscarriage Kahlo undergoes a transition from pathetic victim to serene integration, a metamorphosis in which myth plays the leading part. Kahlo found solace in art as a realm where meaning could be salvaged from the cruel randomness of her fate: "My painting carries within it the message of pain ... painting completed my life. I lost three children.... Painting substituted for all this. I believe that work is the best thing."

However much it is ostensibly about later events, her operations and miscarriages, on another level Kahlo's work registers the enduring consequences of her accident and reflects the mental work needed to overcome this. Her body was broken, its boundaries ruptured and grossly violated by the steel rod that pierced her pelvis and emerged from her vagina. "I lost my virginity," she plaintively remarked. The resulting scars were deeply etched. The Broken Column, 1944 (fig 4) relives that first trauma. It portrays Kahlo isolated in a barren fissured landscape that mirrors her own doleful condition. By using a technique gleaned from medical illustrations her body is shown open to display her shattered spine, a crumbling classical column. The body as a temple has been desecrated and laid to ruin. Kahlo's ongoing anxiety about her body surfaces in a private sketchbook, where, above the image of a frail marionette toppling from a pedestal, she has inscribed, "I am DISINTEGRATION."

The plaster corsets in which Kahlo was encased and which she painted and decorated function symbolically as shields or armour warding off a hostile world. A defensive posture is likewise evident in Self Portrait with Monkey, 1940 (fig 5), in which her face is blankly inexpressive and the space shallow and crowded by excessive foliage. The picture actively rebuffs either psychological or visual penetration by the spectator and hence may be related back to the initial traumatic event. The umbilical cords, arteries, tendrils, roots, and bandages in her canvases are like talismans, signifying connection and promising to heal divisions. Her method of working suggests analogies on an 
imaginative plane with the surgery that aimed at restoring her disrupted physical self. According to an acquaintance, "They had to put her back in sections as if they were making a photomontage," and it is in the form of piecemeal collages that her paintings are constructed. In Self Portrait with Dr Farill, 1951 (fig 6) painted as a thanks offering, this analogy is explicit as her brushes, dripping red paint, evoke surgical scalpels.

The incorporation of overtly medical iconography into Kahlo's painting has thus far been treated as an incidental element subordinate to the aim of articulating her experience. Yet its importance far exceeds this. Kahlo began using medical imagery in 1932 just as Rivera was painting the Detroit murals that include a panel devoted to modern science and medicine. A pamphlet describes him painting on a scaffold "littered with specimens of the objects he chose to represent. Strewn about him were fossils, crystals, fruits, vegetables, books on anatomy. Kahlo too gathered texts of anatomy and obstetrics and in her bedroom kept a fetus in a jar of formaldehyde - a lugubrious gift from her friend Dr Eloesser. Rivera

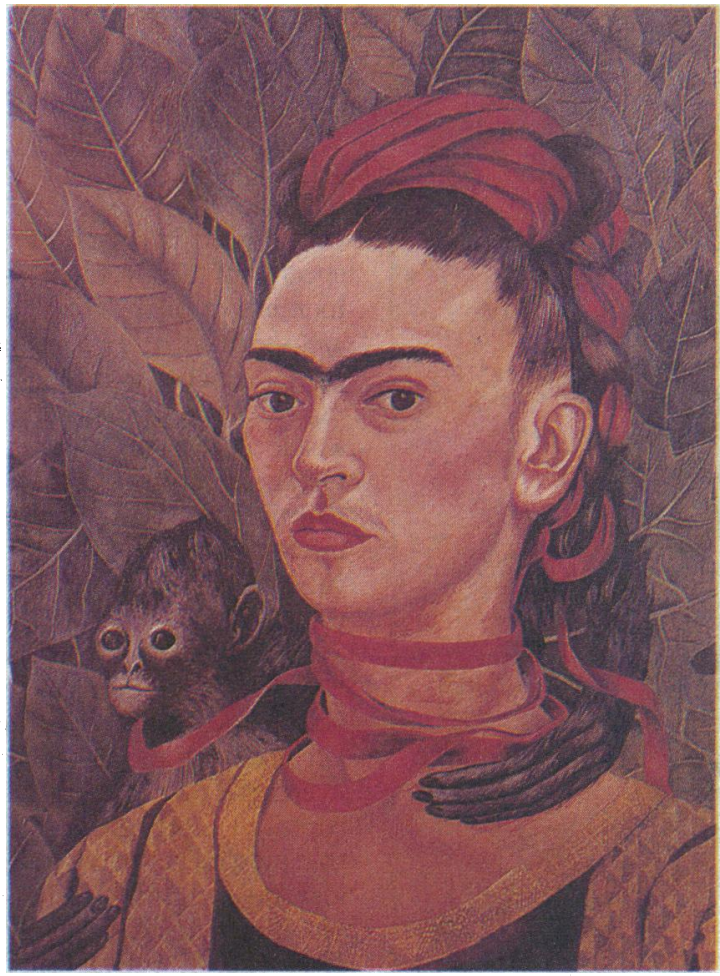

FIG 5-Self portrait with monkey, 1940. Collection of Otto Atencio Trocomis, Caracas

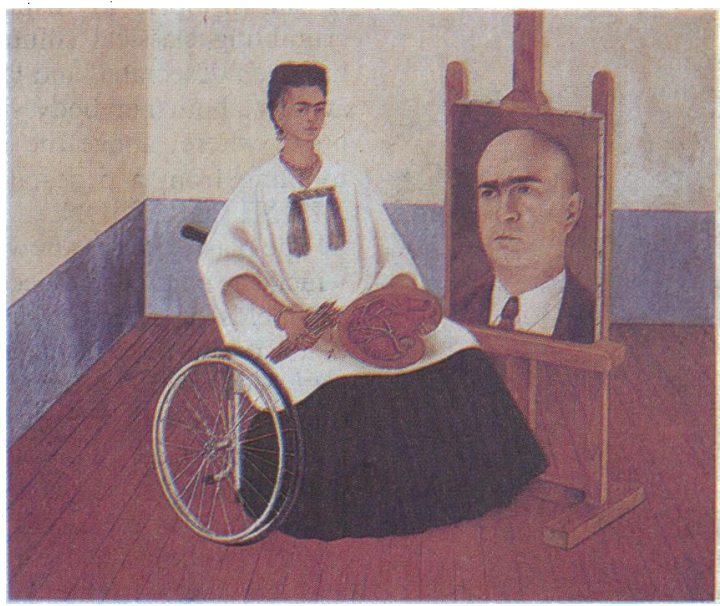

FIG 6-Self portrait with Dr fuan Farill, 1951. Collection of Gallery Arvil, Mexico City

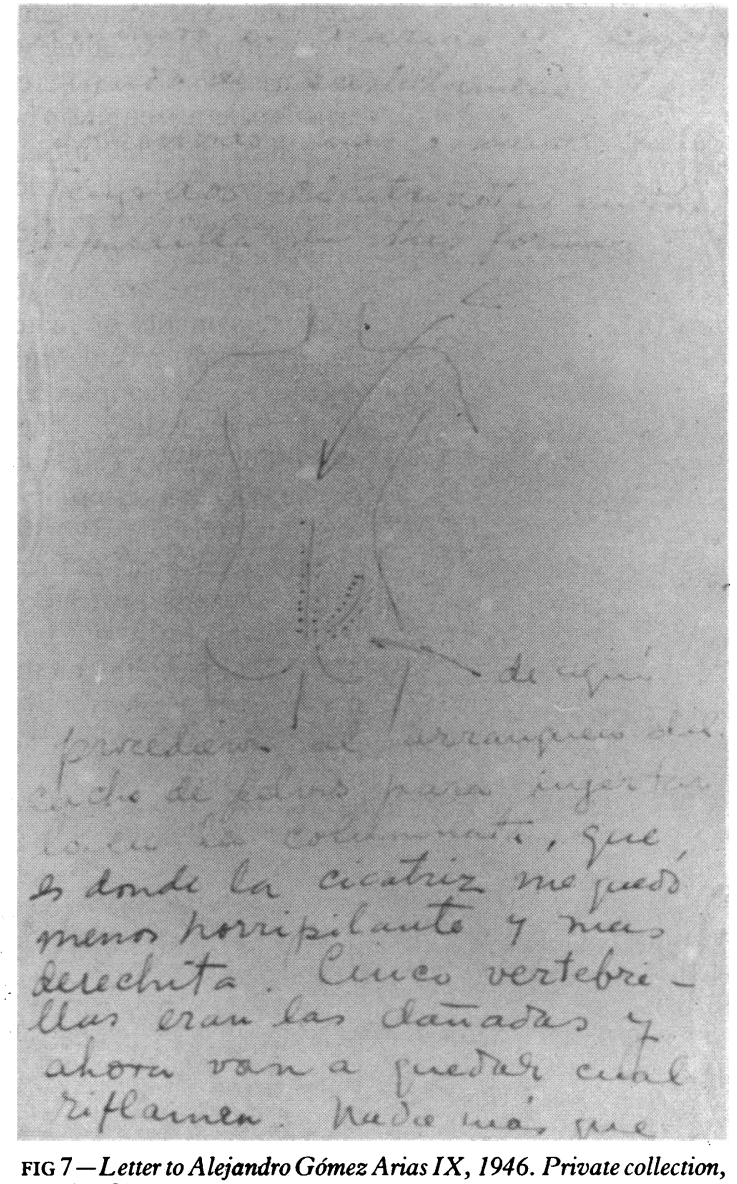

FIG $7-$ Letter
Mexico City

may have provided the initial impetus, but there is a vast disparity between their use of medical imagery.

In 1943-4 Rivera painted two murals of the history of cardiology for the Instituto Nacional de Cardiologia in Mexico City. His brief for the project dictated that the ascent of knowledge be represented by a pantheon of "men striving, striving in an upward march." The murals are dedicated to Dr Chávez, who was inspired to write: "Science was not born today, nor yesterday; it has been gestated painfully through the centuries in the thought of man. The pain of birth and the Faustian joy of creation join at each of the stellar moments of scientific history when an idea, a theory or a discovery comes into being." The florid metaphor of gestation and birth has a cutting edge as only a single woman is included - a patient.

Diego depicts the birth of cardiology while Frida paints scenes of actual childbirth. Where the former are hugely and heroically masculine, the latter are modest in scale and unheroic and speak of female experience. In the murals artistic modernism reinforces the theme of medical progress; art and science are locked in a mutually uplifting embrace. Kahlo, by contrast, uses medical imagery in a disruptive way as a foreign element that causes one to question the boundaries and exclusions enforced by art.

Ironically, as an adolescent Kahlo had embarked on a course of study leading to medical school, but her accident prevented her from pursuing this career. Yet as a patient she later overcomes her dependency on medical authority by pastiche and appropriation of its language. In a letter written after her operation for spinal fusion in 1946 she encloses a casual sketch (fig 7) in the distinctive style and format of medical notation to depict the wounds on her back. Furthermore, it adopts the doctor's viewpoint to scrutinise her body from a position that was physically denied her as a patient. By this inversion she negotiates a degree of autonomy, at least within the field of visual representa- 
tion. A similar strategy can be discerned in other images. In My Birth Herrera notes that the scene is examined from the position of a medical attendant, ${ }^{\prime}$ a viewpoint often used to depict childbirth in obstetric texts. Here the device also heightens the shocking candour of the image.

The knowledge Kahlo sought about her body, "Who knows what the devil is going on inside me," was illicit: her biographer recounts that after her first miscarriage she begged staff to give her textbooks with illustrations of the event but was refused. ${ }^{1}$ A complement to this knowing and ironic mimicry to a forbidden medical genre is her parody of gender. The Self Portrait with Cropped Hair, 1940, best known of her many portraits, was painted.while estranged from Diego. In it she mockingly dons an oversized suit belonging to Rivera as if to deflate his mythical larger than life bravado. The significance of Kahlo's appropriation of medical imagery is bound up with the contradictory predicament of a female intellectual in the 1930s. ${ }^{7}$ Because of her association with Rivera she gained entrance to an emancipated, secular milieu of artists and intellectuals where scandal was courted and that afforded her considerable latitude to confront and affront conventional mores. Maybe she was able to exploit the privileged status of medical imagery to expose parts and functions of the body that decorum normally hides and thus sidestep the strictures of a chauvinist, Catholic society. In Henry Ford Hospital Kahlo dared to display not only her naked body in public but her soiled linen too.

The foregoing images openly declare their medical sources to underline the act of appropriation. In contrast, Self Portrait with Monkey contains a more veiled reference to the medical texts Kahlo so assiduously scoured, but which is none the less integral to the pictorial effect. The red ribbon that winds round her neck confers an air of foreboding and surely refers to obstetric images of cord strangulation, in which the lifeline of a fetus becomes the instrument of its death. Beneath the lavishly painted surface and behind her seemingly impassive mask lurks a sense of impending doom. Small wonder the surrealist poet André Breton would describe her art as a ribbon around a bomb.

Thus one is returned to Kahlo's self portraits. The frank intimacy of her painting almost inevitably dictates a biographical reading. Against the grain of allegorical painting she stridently asserts the validity of her concrete experience as a subject for art. The presence of a particularised subject in Frida and the Miscarriage, where an anonymous female figure would usually appear, exemplifies this. While the events she depicts are intensely personal the language of their expression is not. It is a paradox that given her avowed rejection of Catholicism Kahlo constantly draws on its rich visual traditions; the tears, wounds, and broken hearts are those of the Mater Dolorosa, whom she repeatedly invokes to symbolise her plight. What seems at first

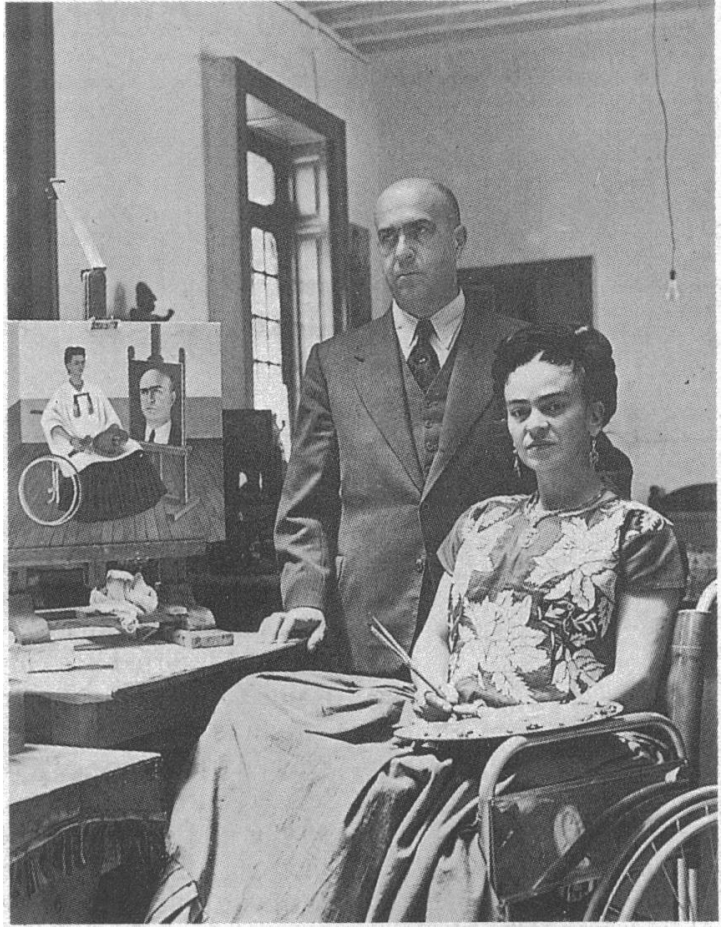

Frida Kahlo and Dr Farill in 1952

sight a spontaneous outpouring of raw emotion is, in fact, distanced and mediated through culture. Rivera, who believed passionately in the political mission of art, insisted that her painting was "individual-collective." ${ }^{2}$ Her body is a site where wider political concerns intersect: the issue of Mexican nationalism versus dependence on a technologically and medically superior North America informs the juxtaposition of motifs drawn from these disparate sources. In pictures such as Frida and the Miscarriage medical anatomy converses on an equal plane with myth and popular Mexican beliefs about the body and illness; each is affirmed as a legitimate source of meaning.

Kahlo used medical imagery to record her own singular history. The paradox is that in doing so she exploded preconceptions of what is permissible in high art and proclaimed a message "individual-collective" in its many resonances.

1 Herrera H. Frida. A biography of Frida Kahlo. New York: Harper and Row, $1983: 50 ; 142 ; 148 ; 157 ; 231$

2 Rivera D. Textos de arte. Mexico City, 1986: 282-93.

3 Hall RC, Beresford TP, Quinones JE. Grief following spontaneous abortion. Psychiatr Clin N Am 1987;3:405-20.

4 Warner M. Alone of all her sex. The myth and the cult of the Virgin Mary. London: Weidenfeld and Nicolson, 1976:206-23.

Anonymous. The Diego Rivera Frescoes. A guide to the murals of the garden court. Anonymous. The Diego Rivera Frescoes. A
Detroit: Detroit Institute of Arts, 1933.

6 Chávez I. Diego Rivera: sus frescoes en el instituto nacional de cardiologia. Mexico City: Sociedad Mexicana de Cardiologia, 1946.

7 Franco J. Plotting woman. Gender and representation in Mexico. London: Verso, 1989.

8 Breton A. Surrealism and painting. London: Macdonald, 1972:141-4.

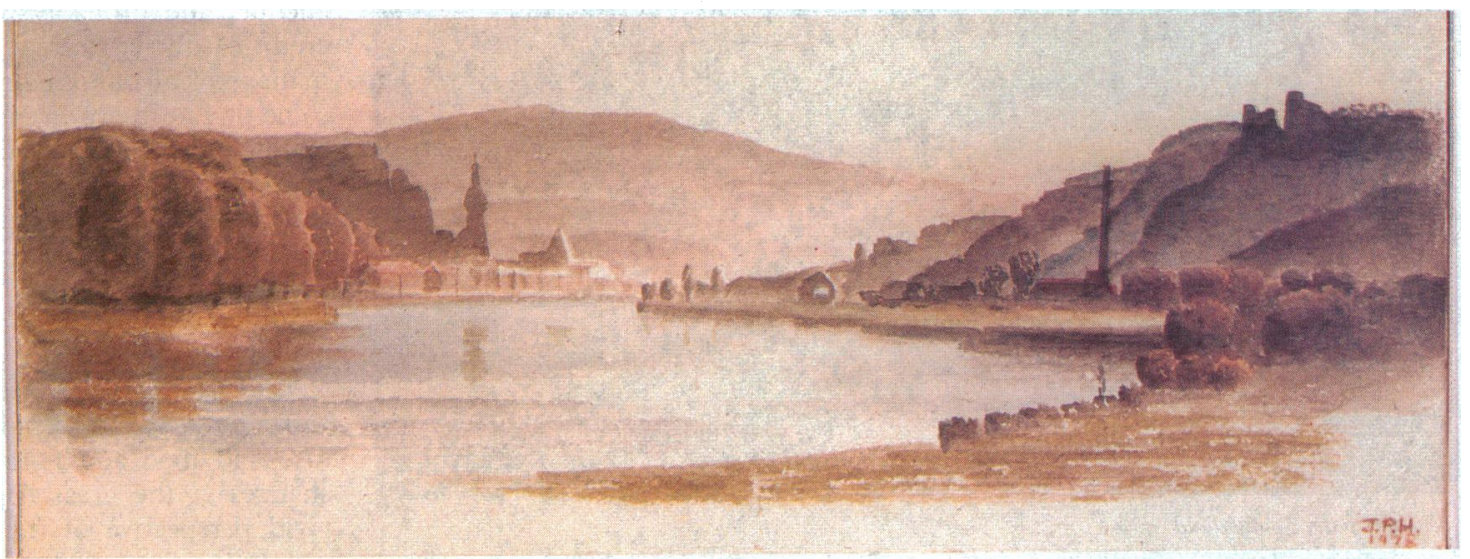

